\title{
Vibrational spectroscopy of chemical warfare agents
}

Samuel P. Hernández-Rivera, Orlando Ruiz-Pesante, Oliva M. Primera-Pedrozo, Leonardo C. Pacheco-Londoño, William Ortiz, Michael L. Ramirez, Yadira M. Soto-Feliciano, and Deborah E. Nieves

The infrared and Raman spectral signatures of chemical threat agents can be used to develop remote sensing chemical-warfare detection systems.

Countering potential terrorist attacks requires a diversified array of detection capabilities designed for a wide range of deployment scenarios. ${ }^{1,2}$ There is also increased awareness concerning the vulnerability of civilian food and water supplies to deliberate contamination by chemical warfare agents (CWAs), typically assumed to target only military personnel and installations. Hence the urgent need for analytical technologies capable of detecting a wide variety of CWAs as well as their hydrolysis and degradation products in complex environments.

Among the analytical techniques available for the detection and identification of chemical agents, ${ }^{2-11}$ vibrational spectroscopy (infrared or Raman) has the advantage of providing accurate chemical information. It also has a potential for remote sensing applications. Raman spectroscopy is especially useful due to its inherent ability to distinguish between molecules that have a high degree of similarity. In our work, we use vibrational spectroscopy to characterize CWAs and also seek to develop a remote sensing technology based on the Raman spectroscopic signature of these chemical threat compounds.

One of our approaches is based on acquiring the Raman spectra of CWAs and their degradation products using different excitation wavelengths. By varying the excitation at the same laser power, we can identify the laser line producing the best Raman signatures for the threat compounds studied. In a series of recently investigated chemical warfare agent simulants (CWASs), optimum excitation was achieved at a laser power of $25 \mathrm{~mW}$ using the 488 and $532 \mathrm{~nm}$ lines. Typical spectra are shown in Figure 1 for 1,6-dichlorohexane. Remote Raman telescope experiments were also performed on CWASs using $488 \mathrm{~nm}$-excitation at a distance of seven meters. We were able to

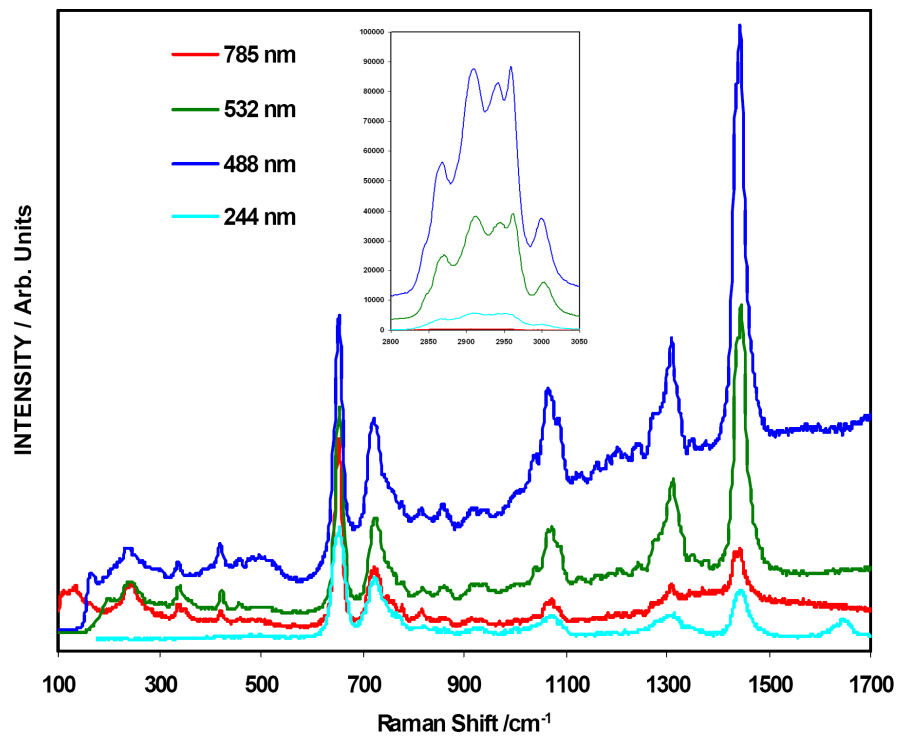

Figure 1. Raman spectra of 1,6-dichlorohexane obtained at different excitation lines. Arb: Arbitrary.

record well-resolved single spectra of dimethyl methyl phosphonate as a function of laser power and integration time, as shown in Figure 2.

Infrared spectroscopy experiments were also carried out on trace compounds deposited on various surfaces. Figure 3 shows the fiber-optic coupled-grazing angle probe Fourier transform infrared (FOC-GAP-FTIR) spectra of 5 and $10 \mu \mathrm{g} / \mathrm{cm}^{2}$ of 2-chloroethyl ethyl sulfide deposited on a stainless steel surface. Results clearly show that limits of detection as low as nanograms $/ \mathrm{cm}^{2}$ (milligrams $/ \mathrm{m}^{2}$ ) are achievable. This methodology also has the advantage of being able to detect CWAs on surfaces as varied as metal, plastic, glass, wood and others. ${ }^{12-14}$

In other experiments, the spectra of CWAs and their degradation products were measured using Raman spectroscopy, liquid and gas phase FTIR, FOC-GAP-FTIR, as well as Raman excitation in the near infrared $(785 \mathrm{~nm})$, visible $(532,514$ and $488 \mathrm{~nm})$ 


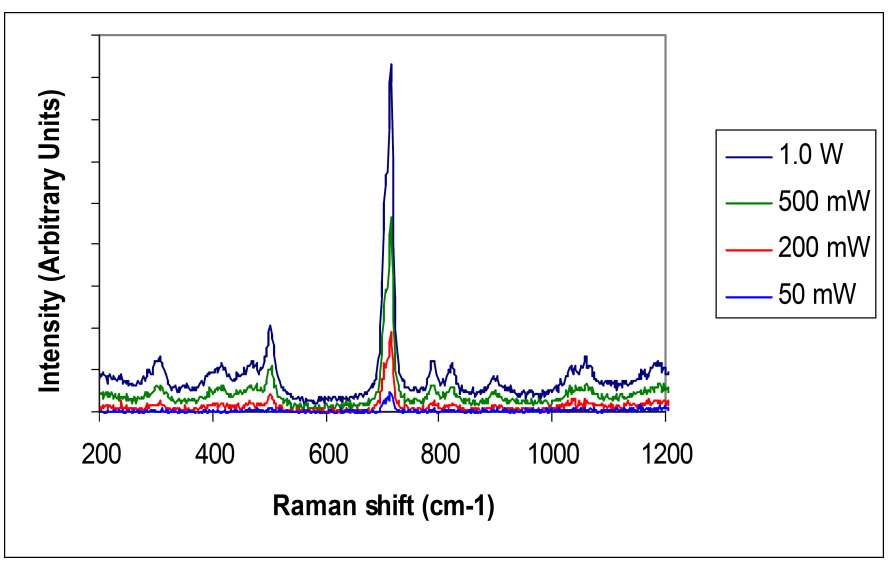

Figure 2. Raman spectra of dimethyl methyl phosphonate as a function of laser power (single acquisitions).

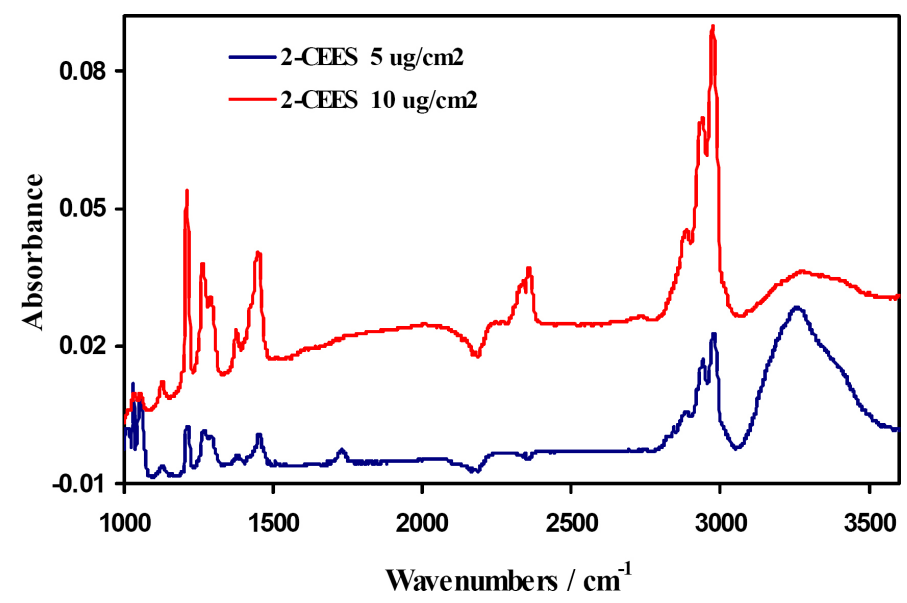

Figure 3. Fiber-optic coupled Fourier transform infrared (FTIR) spectra of 2-chloroethyl ethyl sulfide (2-CEES) deposited on a stainless steel surface.

and deep ultraviolet $(244 \mathrm{~nm})$. The spectra yielded clear and strong signatures suitable for chemical detection in the near or far field, potentially leading to vehicle-borne or man-portable detection systems for use by defense and security agencies or combat troops. Further, we evaluated a method for the detection and quantification of chemical warfare agent simulants on surfaces as proof of concept. In addition, we showed that the technique could be used for the decontamination and cleaning validation processes of these highly toxic compounds.

This work was supported by the University Research Initiative (URI)MURI Program of the U.S. Department of Defense under grant number DAAD19-02-1-0257. The authors also acknowledge contributions from the National Action Council for Minorities in Engineering
(NACME) and the Chemical Imaging Center of the Chemistry Department at the University of Puerto Rico - Mayagüez.

\section{Author Information}

Samuel P. Hernández-Rivera, Orlando Ruiz-Pesante, Oliva M. Primera-Pedrozo, Leonardo C. Pacheco-Londoño, William Ortiz, Michael L. Ramirez, Yadira M. Soto-Feliciano, and Deborah E. Nieves

Center for Chemical Sensors Development

University of Puerto Rico - Mayagüez Campus

Mayagüez, PR

Samuel P. Hernández-Rivera is the Director of the Center for Chemical Sensors Development at the University of Puerto Rico - Mayagüez.

Orlando Ruiz-Pesante is a member of the Center for Chemical Sensors Development at the same university. The focal point of the research carried out at the Center is the detection of chemical threat agents such as explosives, as well as of biological agents and toxic industrial compounds for defense and security applications.

\section{References}

1. Y. Sun and K. Y. Ong, Detection Technologies for Chemical Warfare Agents and Toxic Vapors, CRC Press, Boca Raton, FL, 2005.

2. S. Farquharson, A. Gift, P. Maksymiuk, and F. Inscore, Surface-enhanced Raman spectra of VX and its hydrolysis products, Appl. Spec. 59 (5), pp. 654-660, 2005.

3. V. S. Smentkowski, P. Hagans, and J. T. J. Yates, Study of the catalytic destruction of dimethyl methylphosphonate: Oxidation over Mo(110), J. Phys. Chem. 92 (22), pp. $6351-$ 6357, 1988.

4. T. C. Marrs, R. L. Maynard, and F. R. Sidell, Chemical Warfare Agents: Toxicology and Treatment, John Wiley \& Sons, Chichester, UK, 1996.

5. P. A. D'Agostino, J. R. Hancock, C. L. Chenier, and C. R. Jackson-Lepage, Liquid chromatography electrospray tandem mass spectrometric and desorption electrospray ionization tandem mass spectrometric analysis of chemical warfare agents in office media typically collected during a forensic investigation, J. Chromatogr. A 1110 (1-2), pp. 8694, 2006.

6. D. Pardasani, M. Palit, A. K. Gupta, P. K. Kanaujia, and D. K. Dubey., Gas chromatography-mass spectrometry analysis of trifluoroacetyl derivatives of precursors of nitrogen and sulfur mustards for verification of chemical weapons convention, J. Chromatogr. A 1059 (1-2), pp. 157-164, 2004.

7. P. A. Smith, D. Koch, G. L. Hook, R. P. Erickson, C. R. Jackson, L. Haley, D. M. Wyatt, G. Betsinger, and B. A. Eckenrode, Detection of gas-phase chemical warfare agents using field-portable gas chromatography-mass spectrometry systems: instrument and sampling strategy considerations, Trends Anal. Chem. 23 (4), pp. 296-306, 2004. 8. W. E. Steiner, C. S. Harden, F. Hong, S. J. Klopsch, H. H. Hill Jr., and V. M. McHugh, Detection of aqueous phase chemical warfare agent degradation products by negative mode ion mobility time-of-flight mass spectrometry [IM(tof)MS], J. Am. Soc. Mass Spec. 17 (2), pp. 241-245, 2006.

9. A. B. Kanu, P. E. Haigh, and H. H. Hill., Surface detection of chemical warfare agent simulants and degradation products, Anal. Chim. Acta. 553 (1-2), pp. 148-159, 2005.

10. W. F. Pearman and A. W. Fountain, Classification of chemical and biological warfare agent simulants by surface-enhanced Raman spectroscopy and multivariate statistical techniques, Appl. Spec. 60 (4), pp. 356-365, 2001. 
11. O. M. Primera-Pedrozo, L. C. Pacheco-Londoño, L. F. De la Torre-Quintana, S. P. Hernandez-Rivera, R T. Chamberlain, and R. T. Lareau, Use of fiber optic coupled FT-IR in detection of explosives on surfaces, Proc. SPIE 5403, pp. 237-245, 2004.

12. O. M. Primera-Pedrozo, L. C. Pacheco-Londoño, O. Ruiz, M. Ramirez, Y. M. Soto-Feliciano, L. F. De La Torre-Quintana, and S. P. Hernandez-Rivera, Characterization of thermal inkjet technology TNT deposits by fiber optic-grazing angle probe FTIR spectroscopy, Proc. SPIE 5778, pp. 543-552, 2005.

13. P. Melling and M. Thomson, Fiber Optic Probes for Mid-Infrared Spectrometry, John Wiley \& Sons Ltd., New York, NY, 2002.

14. N. K. Mehta, J. E. Goenaga-Polo, S. P. Hernández-Rivera, D. Hernández, M. A. Thomson, and P. J. Melling, Development of an in situ spectroscopic method for cleaning validation using mid-IR fiber-optics, BioPharm Int. 15, pp. 36-41, May 152002. 